\title{
AOR
}

Selected Papers of \#AolR2020:

The 22nd Annual Conference of the

Association of Internet Researchers

Virtual Event / 13-16 Oct 2021

\section{DEVELOPING A MOBILE GAMES DATABASE: TRACING INTERDEPENDENCIES AMONG EARLY MOBILE GAMES}

Adriana de Souza e Silva

North Carolina State University, USA

Ragan Glover-Rijkse

Methodist University, USA

Today, it is increasingly common to see people walking around the streets, sitting on a bus, or hanging out at cafes and restaurants, playing games on their phones. These games allow people to play almost anywhere, anytime, independent of a tethered internet connection. For this reason, mobile games have become woven into the fabric of daily life, as individuals carry their phones with them on-the-go, squeezing in moments of play or setting aside specific playtimes. Since the release of the iPhone 3G and the App Store in 2008, the number of mobile games has increased substantially, reflecting what Mäyrä (2015) refers to as a growing and increasingly complex genre. Nevertheless, mobile games are not new; they have been around since at least the 1970s, serving as ground building components of today's ludic and digital cultures.

Despite their significance, early mobile games pose challenges to research. The earliest mobile gaming platforms, like Mattel Football and Nintendo Game \& Watch, were handheld electronic consoles. Although many of these games were popular at their time of inception, they are often no longer on the market, ${ }^{1}$ making them difficult or expensive to acquire. By the 1990s, mobile phones also became important platforms for mobile gameplay — with games like Tetris and Snake being redesigned for mobile phones. However, these games became unplayable with the release of new operating systems and, similar to handheld consoles, these mobile phones can be difficult and expensive to acquire. Finally, in the early 2000 s, several media artists, startup companies, and academic researchers started to experiment with mobile devices, such as mobile phones and PDAs, as interfaces for game play (Flintham et al., 2001; Sotamaa, 2002; Wagenknecht \& Korn, 2016). However, these early games were often unavailable to the general public because they were restricted to small research or artistic circles. In addition, since the nature of these games was generally ephemeral (i.e., they were

\footnotetext{
${ }^{1}$ Except on third-party stores for used items, like eBay.

Suggested Citation (APA): de Souza e Silva, A., Glover-Rijkse, R. (2021, October). Developing a Mobile Games Database: Tracing Interdependencies Among Early Mobile Games. Paper presented at AoIR 2021: The 22nd Annual Conference of the Association of Internet Researchers. Virtual Event: AolR.

Retrieved from http://spir.aoir.org.
} 
played during a specific timeframe in a specific location, and then disappeared), it is difficult to find documentation or historical accounts about them, unless a researcher knows specifically how to search for them with exact titles, keywords, and creators. Collectively, these challenges limit our knowledge about the history of mobile games and make it difficult to identify correlations between contemporary and early mobile gaming cultures.

With the goal to provide a research resource for those interested in gaming and digital cultures, we have developed an online, publicly searchable database of early mobile games developed between 1975 and 2008. This database offers game scholars, students interested in games, and game enthusiasts a centralized repository where they can search for games by using a wide range of criteria, such as title, time frame, genre, type of connectivity, number of players, place of development, authors, and hardware. The database also provides a map that shows the geographic location of where the searched games were developed, displays popular press and scholarly articles written about the games, and suggests related games. By combining search criteria, users are able to trace new correlations and interdependencies among games that otherwise might not be evident. Users can also suggest new games and information to the database, contributing to the robustness of this resource.

Understanding and researching the history of mobile games is relevant because mobile games link digital culture and urban mobility, and they promote different types of sociability. Scholars have been looking at the intersection of mobile games and society for quite some (de Souza e Silva \& Sutko, 2009; Ermi \& Mäyrä, 2005; Hjorth \& Richardson, 2014), exploring issues such as how place and space are co-constructed through game play, and how, when, and for what reasons people move while playing games. However, research into the history of mobile games is limited, with a few important exceptions (Chess \& Paul, 2019; Jull, 2009; Mäyrä, 2015; Parikka \& Suominen, 2006). This raises the question: How can researchers better trace the history and correlations among early mobile games?

In this paper, we first discuss our process for developing a historical database of mobile games, emphasizing the interdependent relationship between theory and practice. The database emerged from our theoretical and historical inquiry about the role of mobile games in culture and society. However, during the process of conceptualizing and developing the database, we refined those theories and relationships (and building the database was in itself an exercise in theory-building). Through this process, we developed an understanding about the connections among early mobile games, adding nuance to the categories used to define them.

Second, we discuss interdependence as a value for research, more broadly. This database was developed in collaboration with scholars/practitioners across disciplines and its future robustness depends on the ability to crowd-source information that is scattered across the web and in archives. We argue that the pursuit of interdependence, rather than independence, helps to fuel research, widen our perspectives, and disrupt normative frameworks guiding research. 
It is our hope that the database will significantly improve the process of researching mobile games by centralizing information about these games. We anticipate that this project will not only increase interest in the study of mobile games for game studies scholars and internet researchers but will also serve as a historical record for an increasingly meaningful aspect of culture and social life.

\section{References}

Chess, S., \& Paul, C. A. (2019). The end of casual: Long live casual. Games and Culture, 14(2), 107-118.

de Souza e Silva, A., \& Sutko, D. M. (Eds.). (2009). Digital Cityscapes: Merging digital and urban playspaces. New York: Peter Lang.

Ermi, L., \& Mäyrä, F. (2005). Player-centred game design: Experiences in using scenario study to inform mobile game design. Game Studies.

Flintham, M., Benford, S., Humble, J., Tandavanitj, N., Adams, M., \& Row-Farr, J. (2001). I Like Frank: a mixed reality game for 3G phones. submitted to IEEE Computer Graphics And Applications.

Hjorth, L., \& Richardson, I. (2014). Gaming in Social, Locative and Mobile Media: Palgrave Macmillan.

Jull, J. (2009). A Casual Revolution: Reinventing Video Games and Their Players. Cambridge, MA: The MIT Press.

Mäyrä, F. (2015). Mobile games. The International Encyclopedia of Digital Communication and Society, 1-6.

Parikka, J., \& Suominen, J. (2006). Victorian snakes? Towards a cultural history of mobile games and the experience of movement. Game Studies, 6(1).

Sotamaa, O. (2002). All the world's a Botfighters stage: Notes on location-based multiuser gaming. Paper presented at the Proceedings of computer games and digital cultures conference.

Wagenknecht, S., \& Korn, M. (2016). Hacking as transgressive infrastructuring: Mobile phone networks and the German Chaos Computer Club. Paper presented at the Proceedings of the 19th ACM Conference on Computer-Supported Cooperative Work \& Social Computing. 